\title{
An Empirical Assessment of Factors Influencing Injury Severities of Motor Vehicle Crashes on National Highways of Pakistan
}

\author{
Hanif Ullah $\mathbb{D}^{1},{ }^{1}$ Asim Farooq $\mathbb{D}^{1},{ }^{1}$ and Akhtar Ali Shah $\mathbb{i D}^{2}$ \\ ${ }^{1}$ Department of Civil Engineering, CECOS University of IT and Emerging Sciences, Peshawar, Pakistan \\ ${ }^{2}$ Department of Urban and Regional Planning, University of Peshawar, Peshawar, Pakistan \\ Correspondence should be addressed to Hanif Ullah; hanifullah755@yahoo.com
}

Received 13 April 2021; Revised 2 June 2021; Accepted 17 June 2021; Published 23 June 2021

Academic Editor: Elżbieta Macioszek

Copyright (c) 2021 Hanif Ullah et al. This is an open access article distributed under the Creative Commons Attribution License, which permits unrestricted use, distribution, and reproduction in any medium, provided the original work is properly cited.

Road transport is the dominant mode of transport in Pakistan carrying $91 \%$ of the country's passenger traffic and $96 \%$ of freight traffic. National highways, being $3.7 \%$ of the entire road network, carry $80 \%$ of commercial traffic. Due to the high number of road traffic crashes and resulting fatalities, a random parameters logit model was estimated to determine the risk factors that influence the severity of injuries caused by motor vehicle crashes on national highways. The effects of driver characteristics, crash characteristics, highway characteristics, temporal characteristics, and environmental characteristics were considered for the analysis. From the results, it was revealed that many factors such as overspeeding, driver dozing, driver carelessness, driver age $<25$ years, truck, rickshaw, single vehicle, horizontal curve, potholes, night without road lights, AM peak, Tuesday, weekdays, May, July, November, cloudy weather, clear weather, normal visibility, and wet road surface affect injury severity of the crash victims. The results are expected to be useful for transport planners, traffic managers, road engineers, and other stakeholders both from public and private sectors in prioritizing road sections for improvements and implementing suitable road safety interventions. This will ultimately result in the decreased social and economic burden of road traffic injuries (RTIs).

\section{Introduction}

Globally, around 1.35 million human lives are lost due to road traffic crashes (RTCs) every year. Low- and middle-income countries' share is around $90 \%$ in these fatalities despite having only $54 \%$ of the world's vehicles [1]. The rate of road crash fatalities in Pakistan is unacceptably high which account for approximately 25,781 fatalities per annum [2, 3]. Estimated statistics have revealed that more than $50 \%$ of the RTCs' victims are in the age group of 15 to 44 years. For Pakistan, the economic cost of RTCs and injuries is estimated to be more than 100 billion rupees [4]. Compared to other modes, road transport is overwhelmingly dominant in Pakistan carrying $91 \%$ of the country's passenger traffic and $96 \%$ of freight traffic [5]. About $65 \%$ of the country's traffic load is carried by the longest national highway-5 (N-5), known as the lifeline of the country's economy [6].
Despite alarming road traffic crash statistics, very limited studies have focused on road safety issues in Pakistan [7-14]. A few recent studies investigated injury severity of road users including motorcyclists' injury severity in urban settings [15] and crash victims' injury severity on motorways [16]. To the author's best apprehension after a thorough literature review, no study has investigated the factors influencing injury severities of motor vehicle crashes (MVCs) on national highways of Pakistan. The accident studies conducted elsewhere in the world incorporate their indigenous roadway, traffic, environmental, and road users' behavioral characteristics. Results from those studies may not be transferrable to the Pakistani context due to significantly different roadway, traffic, environmental, and road users' behavioral characteristics [17]. Mixed traffic, congested lanes, roadside businesses, no access control, low level of enforcement, and aberrant 
behavior of road users are the major characteristics of road environment in Pakistan. Thus, the factors that significantly affect the injury severities of MVCs along national highways of Pakistan are unknown and a fundamental bottleneck in improving road safety in Pakistan. So, it is necessary to comprehensively understand the impact of various risk factors contributing to the injury severities of MVCs on national highways of Pakistan so that appropriate safety interventions can be identified and implemented to reduce the frequency and severity of these crashes. The current study investigated injury severity of MVCs on national highways of Pakistan. Crash data for N-5 were obtained from National Highways and Motorway Police ( $\mathrm{NH}$ and MP) for the development of a random parameters logit model with the purpose to determine major contributing factors to injury severities caused by MVCs.

\section{Literature Review}

From the precedent research efforts, a vast array of factors were determined to be related to RTCs of various injury severity levels [18-23]. Common factors revealed by the literature as associated with increased injury severity of RTCs are speeding $[24,25]$, increased driver or rider age [26], driving under the influence of alcohol [27-30], road alignment [26, 28], darkness [31-35], crashes involving heavy commercial vehicles and motorcycles $[18,24,36]$, and head-on-collisions $[20,28]$. Diverse modeling approaches have been utilized by researchers in earlier studies for the estimation of road crash injury severities. These methods include artificial neural networks [37, 38], Bayesian ordered probit [26], classification and regression tree $[19,39]$, loglinear model [39], Bayesian hierarchical binomial logit [40], Markov switching multinomial logit [41], binary logit and binary probit $[18,42-45]$, mixed generalized ordered logit [20], multinomial logit [46], nested logit [28, 47], ordered logit, and ordered probit $[38,48,49]$ models.

These conventional models are unable to allow variation in explanatory variables across individual outcomes. It is the main limitation of these models. In reality, the response of individual outcome to an explanatory variable is different and thus cannot be considered as fixed. Also, the injury severity of MVCs could potentially be affected by some unobserved factors for which the data is either impossible or very difficult to obtain. Overpassing these factors may cause erroneous inferences and biased estimates of parameters [50]. To resolve the issue of unobserved heterogeneity, researchers have been constantly trying to use models with unbiased parameter estimates and accurate inferences. Such models include latent-class models with random parameters [51], Markov switching model with random parameters [52], random parameters with heterogeneity in means [22, 53], and random parameters with heterogeneity in means and variances [15]. Mixed logit models, that is, random parameters logit models, are the most popular and frequently used models in injury severity studies [53-55]. These models are capable of capturing unobserved heterogeneity in the crash data and discovering complex relationships between injury severities and crash contributing factors.

\section{Data Description}

The route selected for the study was the $953 \mathrm{~km}$ section of N-5 (North Zone from Peshawar to Lahore and central zone from Lahore to Rahim Yar khan Khan) as shown in Figure 1. $\mathrm{N}-5$ is an $1819 \mathrm{~km}$ long major arterial connecting Karachi with the Torkham (Afghan Border). Crash information for the examination was obtained from NH and MP Rawalpindi office for a five years' time frame from January 2015 to December 2019. NH and MP is a police force responsible for the safety and security of national highways and motorways. It also maintains the record of RTCs by filling a crash investigation form at the site immediately after the occurrence of the crash. For recording crash minutiae, a four-page crash Proforma is utilized by the NH and MP which is called Microcomputer Accident Analysis Proforma (MAAP). MAAPs for 2023 crashes were obtained from NH and MP Rawalpindi office. MAAP records victim and driver's demographics (age and gender), temporal details (time, date, month, and year of the crash), environmental details (weather and visibility characteristics), type of vehicle, victim's injury severity level sustained during the crash, and the dominant crash cause. Injury levels based on severity are classified into four categories: fatal injury, major injury, minor injury, and no injury.

In our dataset, 2023 crashes had complete information, out of which 122 (6.03\%) were no injury, 140 (6.93\%) were minor injury (crashes in which the victims sustain injuries that are not life-threatening like abrasions or minor cuts with little or no bleeding), 602 (29.75\%) were major injury (crashes in which at least one of the injured persons is admitted in hospital, e.g., head, neck, or spinal injury and excessive bleeding), and 1159 (57.29\%) were fatal injury crashes (crashes in which at least one injured person die on the same day). It was also revealed from the crash information statistics that the majority of the sufferers were drivers $(78.35 \%)$ contrasted with pedestrians and passengers. As female driving on national highways is very rare due to social and cultural constraints, male victims are dominant (92.98\%) while females' share in fatalities and injuries is very less $(7.02 \%)$. Crashes in dry weather were much more in numbers $(92.24 \%)$ than crashes in wet weather $(7.76 \%)$. The frequency of crashes during the daytime was high (68.41\%) as compared to the crashes during the night (31.59\%).

It was noticed that RTCs frequency was higher during the spring and summer seasons (March to August) (65.59\%). In most of the crashes (87.70\%), driver age was between 25 and 50 years. Likewise, crash frequency was higher during dry weather $(60.15 \%)$ and in the off-peak period $(66.74 \%)$. The majority of crashes occurred in urban sections (61.65\%) compared to rural sections (38.35\%). The dataset revealed that the frequency of multivehicle collision is more (65.65\%) as compared to single-vehicle collision (34.35\%). Table 1 shows descriptive statistics of variables.

\section{Methodology}

Following the recent works $[15,54,55]$, a random parameters (mixed) logit model was estimated considering heterogeneity in means and variances to determine critical factors 


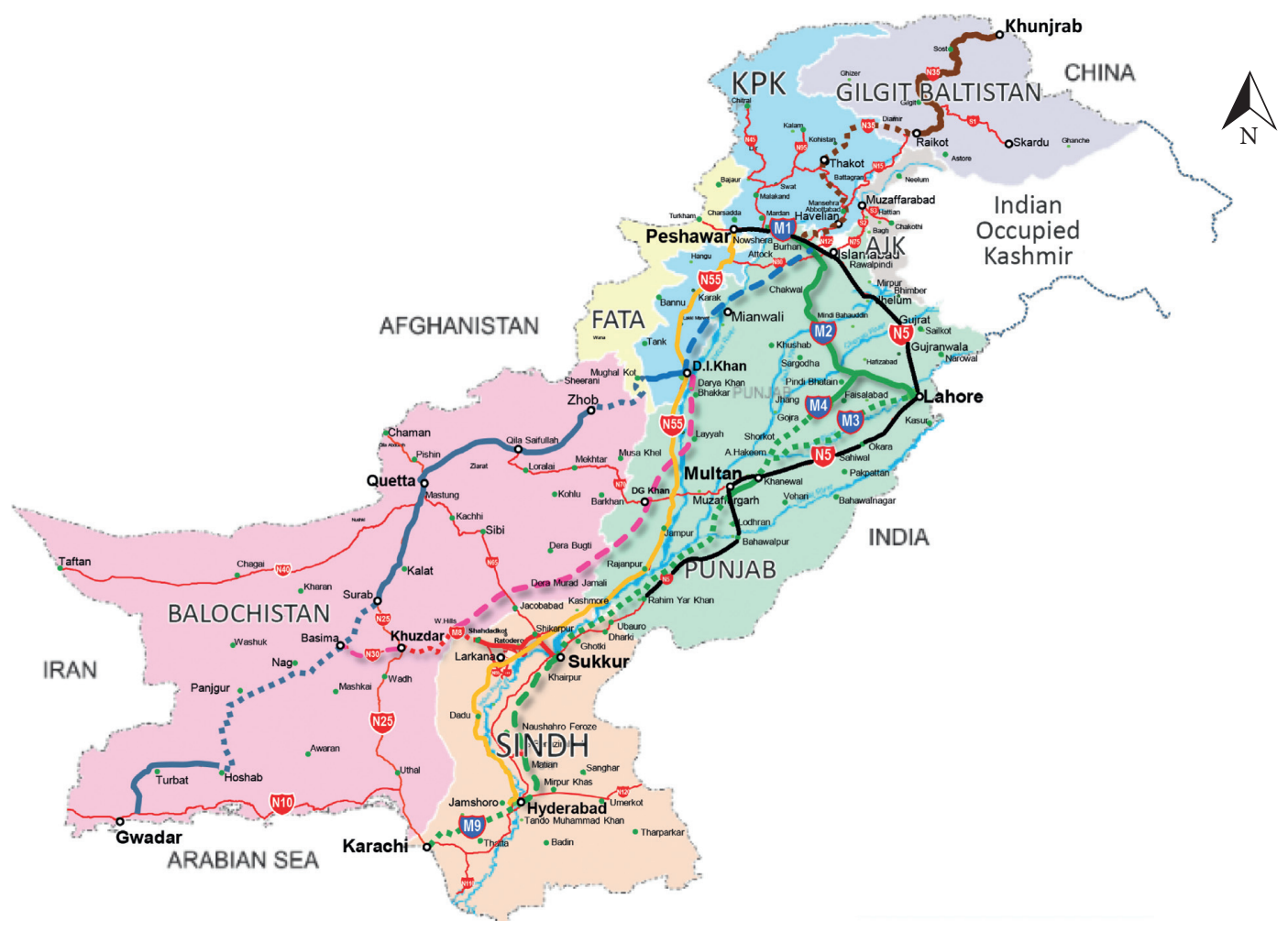

FIgURE 1: Segment of national highway-5 selected for the study.

TABLE 1: Descriptive statistics of variables.

\begin{tabular}{|c|c|}
\hline Variables & Percentage \\
\hline $\begin{array}{l}\text { Crash injury severity } \\
\text { No/minor/major/fatal }\end{array}$ & $6.03 / 6.93 / 29.75 / 57.29$ \\
\hline $\begin{array}{l}\text { Month } \\
\text { January/February/March/April/May/June } \\
\text { July/August/September/October/November/December }\end{array}$ & $\begin{array}{l}6.26 / 4.41 / 10.43 / 11.22 / 9.14 / 9.39 \\
14.68 / 10.73 / 7.99 / 5.16 / 5.38 / 5.21 \\
\end{array}$ \\
\hline $\begin{array}{l}\text { Day } \\
\text { Monday/Tuesday/Wednesday/Thursday/Friday/Saturday/Sunday } \\
\text { Weekday/weekend }\end{array}$ & $\begin{array}{l}16.26 / 11.9 / 11.41 / 13.34 / 14.73 / 17.59 / 14.6 \\
69.25 / 30.75\end{array}$ \\
\hline $\begin{array}{l}\text { Weather conditions } \\
\text { Sunny/cloudy/rainy }\end{array}$ & $60.15 / 22.85 / 17.00$ \\
\hline $\begin{array}{l}\text { Season } \\
\text { December-February (winter)/March-May (spring) } \\
\text { June-August (summer)/September-November (autumn) }\end{array}$ & $\begin{array}{l}15.88 / 30.79 \\
34.80 / 18.53 \\
\end{array}$ \\
\hline $\begin{array}{l}\text { Time of the day } \\
12 \text { a.m.-3 a.m./3 a.m. }-6 \text { a.m./6 a.m. }-9 \text { a.m./9 a.m. }-12 \text { p.m. } \\
12 \text { p.m. }-3 \text { p.m./3 p.m.-6 p.m./6 p.m. }-9 \text { p.m./9 p.m.-12 p.m. } \\
\text { (AM peak: } 7: 30 \text { a.m. to } 10: 30 \text { a.m., PM peak, } 4: 30 \text { p.m. to } 7: 30 \text { p.m., off-peak hours) }\end{array}$ & $\begin{array}{c}6.12 / 8.50 / 14.58 / 14.43 \\
16.36 / 17.30 / 14.33 / 8.35 \\
16.75 / 16.51 / 66.74\end{array}$ \\
\hline $\begin{array}{l}\text { Driver age } \\
<25 \text { years } / 25-50 \text { years/over } 50 \text { years }\end{array}$ & 7.71/87.70/4.59 \\
\hline $\begin{array}{l}\text { Gender } \\
\text { Male/female }\end{array}$ & $92.98 / 7.02$ \\
\hline $\begin{array}{l}\text { Surface condition } \\
\text { Dry/wet }\end{array}$ & $92.24 / 7.76$ \\
\hline $\begin{array}{l}\text { Light condition } \\
\text { Day/night }\end{array}$ & $68.41 / 31.59$ \\
\hline $\begin{array}{l}\text { Road type } \\
\text { Urban/rural }\end{array}$ & $61.65 / 38.35$ \\
\hline $\begin{array}{l}\text { Crash specification } \\
\text { Single vehicle/multiple vehicle }\end{array}$ & $34.35 / 65.65$ \\
\hline
\end{tabular}


influencing injury severity of MVCs on national highways of Pakistan. Lack of some variables in our data set (driving license, operating speed, and traffic condition during crash occurrence) could potentially affect the impact of observed variables on crash severity by inducing unobserved heterogeneity and may result in biased estimates of parameter and wrong inferences [50]. The model estimated allows variation in mean and variance of random parameters across observations so that observation-specific variation in the effect of independent variables may be captured in the best possible manner $[15,55]$. Crash severity function is defined as [56]

$$
M_{\text {in }}=\beta_{i} X_{i n}+\varepsilon_{i n}
$$

where $M_{i n}$ determines injury severity for category $i$ for crash $n ; X_{i n}$ is the explanatory variable vector, $\beta_{i}$ is the estimable parameter vector for discrete outcome $i$; and $\varepsilon_{i n}$ is the error term.

To account or unobserved heterogeneity, $\beta_{i}$ is allowed to vary across crashes and is defined as $[15,55,56]$

$$
\beta_{i}=\beta+\Theta_{i} Z_{i}+\sigma_{i} \operatorname{EXP}\left(\omega_{i} W_{i}\right)_{v i},
$$

where $\beta$ represents the mean parameter estimate across all observations and $Z_{i}$ and $W_{i}$ are attribute vectors used for capturing heterogeneity in the mean and standard deviation $\sigma_{i}$, with corresponding parameter vector $\omega_{i}$.

The estimable parameters vector is $\Theta_{i}$ and the disturbance term is $v_{i}$. The error term $\varepsilon_{i n}$ is assumed as generalized extreme value distributed that results in model probabilities allowing for parameters to vary across crashes and are defined as [57]

$$
\begin{gathered}
P n(i)=\int\left[\beta_{i} X_{i n}\right] f\left(\frac{\beta_{i}}{\varphi_{i}}\right) d \beta_{i} \\
\sum E X P\left[\beta_{I} X_{i n}\right],
\end{gathered}
$$

where $P n(i)$ represents the probability of crash severity outcome $i$ for specified crash $n$ and $I$ represents set of injury severity categories. $f(\beta / \varphi)$ is the density function of $\beta$ with $\varphi$ referring to a vector of density function parameters. To account for unobserved heterogeneity, $\beta$ is determined using the density function $f(\beta / \varphi)[56]$. The probabilities are estimated by drawing values of $\beta$ from the density function $(f(\beta / \varphi))$ for given values of $f$. Model estimation was done utilizing the maximum likelihood approach and using Halton draws. Increased effectiveness of Halton draws over random draws is frequently cited in the literature [58].

For estimation of the model, 500 Halton draws were used which are enough for accurate parameter estimation as indicated by some previous studies [56, 58, 59]. Normal distribution was used as it provided the best statistical fit for the functional form of parameter density function which is also indicated by some prior studies $[60,61]$.

\section{Results}

Model estimation results are presented in Table 2, marginal effects of the significant variables are presented in Table 3, and goodness-of-fit of the estimated model is presented in
Table 4. Some discussion about the significant variables has been carried out in the subsequent paragraphs.

\section{Discussion}

Some discussion about the significant variables has been carried out in the succeeding paragraphs.

6.1. Driver Characteristics. Overspeeding was found to be associated with decreased probability of no injury crashes and increased probability of injury crashes. A similar finding has been revealed by many studies conducted in the past [62-64]. The level of police enforcement on national highways is relatively low as compared to the motorways; that is why overspeeding by the drivers is common on these highways. Further, the speeding penalties are low and there is no legislation such as a demerit points system for repeat offenders.

To reduce the number and severity of crashes, overspeeding violations need to be reduced. This is possible by using behavior modification techniques to drivers based on the theory of planned behavior [65], thorough monitoring through speed cameras, an increase in violation penalties and by introducing demerit points and license suspension system.

Driver age less the 25 years was found to be associated with an increased likelihood of minor injuries and a decreased likelihood of other injury categories. Being inexperienced and careless, there are more chances for younger drivers to be involved in crashes, but being in healthy condition without any deterioration of physical and mental abilities, they can perceive the risk and cope with the situation better than the aged drivers $[66,67]$. Contrarily, older drivers, when injured in crashes, have an increased risk of fatality $[68,69]$ and experience more severe injuries even in nonfatal crashes.

Drivers' dozing at wheel was found to be associated with a lesser possibility of minor injury crash causation and greater possibility of major or fatal injury crash causation. Driving for many hours without taking any rest can lead the driver to drowsiness. It reduces the judgment and decisionmaking capabilities of the driver, thus increasing his/her response time to cope with a certain situation. This increases the risk of high severity RTCs. Due to the lack of hours-ofservice regulations for commercial vehicle drivers in Pakistan, dozing-related crashes are common in these heavy vehicles, which in turn is a major factor, increasing injury severity of crashes. Dozing at wheel has been recognized as one of the key crash risk factors in past research $[10,63,70]$.

Crashes in which driver carelessness was reported as the cause of the crash were found less likely to cause minor injury to the victims and more like to cause injuries of other severity levels. Carelessness of drivers may be in many forms that mainly include either distraction or not following traffic control. Some past studies $[25,71]$ also revealed that carelessness of drivers substantially increases the chances of crash occurrence and the resulting injury severities. 
TABLE 2: Estimated model results for crash severity outcomes.

\begin{tabular}{|c|c|c|}
\hline Variable & $\begin{array}{l}\text { Parameter } \\
\text { estimate }\end{array}$ & t-stat \\
\hline \multicolumn{3}{|l|}{ Fatal injury } \\
\hline Constant (standard error of parameter distribution) & $-11.57(4.050)$ & $\begin{array}{l}-3.071 \\
(2.572)\end{array}$ \\
\hline July indicator ( 1 if crash occurred in the month of July, 0 otherwise) & 0.60685 & 2.24 \\
\hline Weekday indicator ( 1 if crash occurred during weekday, tractor or truck, 0 otherwise) & -0.53878 & -2.82 \\
\hline Truck indicator ( 1 if truck was involved in crash, 0 otherwise) & 0.52432 & 2.70 \\
\hline $\begin{array}{l}\text { Night without road lights indicator ( } 1 \text { if crash occurred at night without road lights, } 0 \text { otherwise) } \\
\text { (standard error of parameter distribution) }\end{array}$ & $0.93067(1.524)$ & $4.92(2.849)$ \\
\hline \multicolumn{3}{|l|}{ Major injury } \\
\hline Constant & -0.870 & -6.645 \\
\hline November indicator ( 1 if crash occurred in the month of November, 0 otherwise) & 0.41588 & 2.31 \\
\hline Cloudy weather indicator ( 1 if crash occurred in cloudy weather, 0 otherwise) & 1.02062 & 3.37 \\
\hline Curve indicator ( 1 if crash occurred at horizontal curve, 0 otherwise) & 0.33802 & 2.76 \\
\hline Tuesday indicator ( 1 if crash occurred on Tuesday, 0 otherwise) & 0.26790 & 1.80 \\
\hline $\begin{array}{l}\text { Pothole indicator ( } 1 \text { if potholes were present in road, } 0 \text { otherwise) (standard error of parameter } \\
\text { distribution) }\end{array}$ & $-0.47476(1.524)$ & $\begin{array}{l}-1.73 \\
(2.849)\end{array}$ \\
\hline \multicolumn{3}{|l|}{ Minor injury } \\
\hline AM peak indicator ( 1 if crash occurred during AM peak hours, 0 otherwise) & -0.43013 & -2.56 \\
\hline Driver dozing indicator ( 1 if crash cause was driver dozing, 0 otherwise) & -0.70923 & -2.28 \\
\hline Driver age $<25$ years indicator ( 1 if driver age was less than 25 years, 0 otherwise) & 0.68938 & 3.91 \\
\hline $\begin{array}{l}\text { Driver carelessness indicator ( } 1 \text { if crash was caused by driver carelessness, } 0 \text { otherwise) (standard error of } \\
\text { parameter distribution) }\end{array}$ & $-0.26214(1.107)$ & $\begin{array}{l}-2.50 \\
(1.829)\end{array}$ \\
\hline \multicolumn{3}{|l|}{ No injury } \\
\hline Constant & -2.651 & -21.30 \\
\hline Overspeeding indicator ( 1 if crash occurred due to overspeeding, 0 otherwise) & -0.80809 & -1.88 \\
\hline Wet road surface indicator ( 1 if road surface was wet during crash, 0 otherwise) & 0.92734 & 2.78 \\
\hline May indicator ( 1 if crash occurred in the month of May, 0 otherwise) & -1.56146 & -2.16 \\
\hline Rickshaw indicator ( 1 if rickshaw was involved in crash, 0 otherwise) & 0.48651 & 2.40 \\
\hline Clear weather indicator ( 1 if crash occurred in clear weather, 0 otherwise) & -0.55810 & -2.01 \\
\hline Single-vehicle indicator ( 1 if single vehicle is involved in crash, 0 otherwise) & 0.00142 & 2.35 \\
\hline Normal visibility indicator ( 1 if crash occurred during normal visibility conditions, 0 otherwise) & -0.53013 & -1.69 \\
\hline \multicolumn{3}{|l|}{ Model statistical fitness } \\
\hline McFadden pseudo-R-squared & 0.27349959 & \\
\hline Restricted log-likelihood & -2804.47349 & \\
\hline Log-likelihood at convergence & -2037.46155 & \\
\hline Akaike information criteria & 4124.9 & \\
\hline
\end{tabular}

6.2. Vehicle Characteristics. Crashes involving rickshaws were found to be more likely to cause no injury crashes. This finding is intuitive due to the relatively lesser speed and weight characteristics of the rickshaw. Past studies revealed that the height, weight, and size of the vehicles involved can significantly influence the injury severity of the crash [72]. A similar finding has been demonstrated in a previous study done in Pakistan [16]. On the other hand, crashes involving trucks were found significant in causing fatal injuries. Being the vehicles with the highest momentum due to larger dimensions, weight, and reasonable fast speed, trucks are logically more likely to cause fatal injuries to the victims. It has also been revealed by some previous studies [73, 74].

6.3. Crash Characteristics. Crashes involving a single vehicle are found more likely to cause no injury crashes. Besides hitting a stationary object, a larger number of single-vehicle collisions involve overturning and lateral skidding of the vehicle, thus lesser damaging impact to the victims. A good agreement can be found among past studies and this finding.
A past study [75] revealed that crashes due to vehicle skidding result in slight injuries. Another study showed that rickshaws are commonly involved in single-vehicle crashes [76]. Past studies also showed that head-on collisions are associated with increased injury severity $[20,77,78]$ while the same direction sideswipe crashes and rear-end collisions result in lower injury severity crashes [79]. Thus, due to lesser impact, low momentum of small vehicles (that probably constitute the higher percentage of single-vehicle crashes), single-vehicle crashes significantly contribute to no injury crashes.

6.4. Roadway Characteristics. Crashes that occurred on horizontal curves are found significant for causing major injury to the victims. It is also evident from the previous research efforts that horizontal curves are the dangerous road segments for both crash frequency and injury severity, specifically curves with relatively lower radii $[31,40,57]$. The variable presence of potholes in the road is found to be less likely for crashes causing major injury to the victims and 
TABLE 3: Estimated marginal effects of the model.

\begin{tabular}{|c|c|c|c|c|}
\hline Variable & Fatal injury & Major injury & Minor injury & No injury \\
\hline \multicolumn{5}{|l|}{ Fatal injury } \\
\hline July indicator & -0.0004 & -0.0015 & -0.0029 & 0.0048 \\
\hline Weekday indicator & 0.0014 & 0.0057 & 0.0112 & -0.0183 \\
\hline Truck indicator & -0.0013 & -0.0060 & -0.0115 & 0.0189 \\
\hline Night without road lights indicator & -0.0017 & -0.0074 & -0.0133 & 0.0225 \\
\hline \multicolumn{5}{|l|}{ Major injury } \\
\hline November indicator & -0.0012 & -0.0047 & 0.0069 & -0.0010 \\
\hline Cloudy weather indicator & -0.0013 & -0.0038 & 0.0058 & -0.0007 \\
\hline Curve indicator & -0.0113 & -0.0455 & 0.0664 & -0.0097 \\
\hline Tuesday indicator & -0.0012 & -0.0046 & 0.0067 & -0.0009 \\
\hline Pothole indicator & 0.0005 & 0.0022 & -0.0032 & 0.0005 \\
\hline \multicolumn{5}{|l|}{ Minor injury } \\
\hline AM peak indicator & 0.0010 & -0.0084 & 0.0070 & 0.0005 \\
\hline Driver dozing indicator & 0.0005 & -0.0039 & 0.0031 & 0.0004 \\
\hline Driver age $<25$ years indicator & -0.0012 & 0.0122 & -0.0100 & -0.0011 \\
\hline Driver carelessness indicator & 0.0032 & -0.0312 & 0.0251 & 0.0029 \\
\hline Wet road surface indicator* & -0.0010 & 0.0075 & -0.0057 & -0.0007 \\
\hline \multicolumn{5}{|l|}{ No injury } \\
\hline Overspeeding & -0.0023 & 0.0008 & 0.0014 & 0.0001 \\
\hline May indicator & -0.0015 & 0.0005 & 0.0009 & 0.0001 \\
\hline Rickshaw indicator & 0.0080 & -0.0025 & -0.0050 & -0.0004 \\
\hline Clear weather indicator & -0.0323 & 0.0102 & 0.0199 & 0.0022 \\
\hline Single-vehicle indicator & 0.0020 & -0.0006 & -0.0013 & -0.0001 \\
\hline Normal visibility indicator & -0.0030 & 0.0010 & 0.0018 & 0.0002 \\
\hline
\end{tabular}

TABle 4: Goodness-of-fit of the competing models.

\begin{tabular}{lcc}
\hline Model statistics & Model with no heterogeneity in means & Model with heterogeneity in means \\
\hline Number of parameters & 24 & 25 \\
Restricted log-likelihood & -2804.47349 & -2804.47349 \\
Log-likelihood at convergence & -2039.10251 & -2037.46155 \\
Akaike information criteria (AIC) & 4126.2 & 4124.9 \\
Bayesian information criteria (BIC) & 4265.23 & 4260.901 \\
Number of observations & 2023 & 2023 \\
\hline
\end{tabular}

thus more likely to cause crashes of other severities. From the previous literature, the relationship between road surface conditions and crash occurrence or injury severity is not very clear [80]. A study by Li et al. [81] revealed that poor road surface condition increases the probability of more severe crashes compared to fair surface conditions while very poor pavement conditions do not contribute significantly to more severe crashes. Another study revealed that, for pavements in poor condition, the surface condition variable has a significant random parameter [82]. The presence of potholes may increase the chances of crash occurrence as the drivers sometimes abruptly change the lane to avoid a pothole. But, the speed of the vehicle at the badly maintained road is usually slower than that on the road with good ride quality. Further, on a divided highway, the crashes are usually side collisions at less than $90^{\circ}$ angle, thus decreasing the chances of major injuries to the victims.

6.5. Temporal Characteristics. Crashes that occurred during AM peak hours (07:30 a.m. to 10:00 a.m.)) were found less likely to cause minor injury crashes and more likely to cause major and/or fatal injury crashes. It may be due to the fact that motor vehicle drivers tend to drive faster in the early morning [83] striving to reach their workplaces in time and faster speeds are associated with higher injury severity [25]. Also, the fog in the winter season prevails in some rural sections of the selected route where traffic volume is relatively less and the drivers are free to move faster which may contribute to higher levels of injury severity. Another reason may be that many commercial vehicle drivers drive alone for the whole night without rest and thus, during morning hours, their reflexes slow down due to drowsiness that leads to the causation of higher injury crashes. Crashes involving trucks and dozing at wheel are also significant factors in our study. Some prior investigations also revealed the same finding $[50,84,85]$.

Crashes that occurred in the month of May are found more likely to cause injury crashes and less likely to cause no injury crashes. No significant evidence has been found in the previous literature about the positive relationship between injury severities and the month of May. This finding may be attributed to the medium temperature and clear weather in the month of May that encourage people to travel more. 
Clear weather and more miles travel are frequently revealed by the researchers as positively associated with injury severity of crashes [86-88]. The summer months of June, July, and August are extremely hot in most areas of Pakistan, specifically along our study route and the fact about more miles travel in summer months in the colder regions is not applicable to our indigenous climate.

Crashes that occurred in the month of November are found more likely to cause major injury crashes. November is the start of winter and so the start of fog along the route. The causation of major injury may be attributed to the fog prevailing at various road segments of the selected highway section. Previous studies also indicated that fog is associated with severe injuries [88-90].

Crashes that occurred in the month of July are found more likely to cause major injury crashes. It is also evident from past studies that high atmospheric temperature is associated with crashes of severe injuries [28]. The same finding was revealed by another study on motorways of Pakistan [16]. Another study in the US showed that summer months experience more fatal crashes, probably due to more vehicle travel [83]. But in Pakistan, it may be attributed to the hydroplaning phenomenon due to wet road surfaces as the monsoon season begins in early July.

One of the unique results of our study is that crashes that occurred on Tuesday are more likely to cause major injury. In contrast, one of the past studies showed that Tuesday is the safest day of the week to drive with lesser crashes and lower injury severities [91]. This finding may be due to the weekly cattle markets at different locations held on roadsides, mostly on Tuesday, which increase the traffic and pedestrian volume. Most of the people in cattle markets are cattle owners or buyers with no or less sense in regard to traffic rules. This may enhance injury severity of victims when the crash occurs at or near such places.

The weekday indicator is found less likely to cause fatal injury crashes. It might be due to the lower operating speeds of vehicles on weekdays owing to high traffic volume, reducing the chances of fatal injuries to the victims. Some prior studies also revealed the same finding [37, 92].

6.6. Environmental Characteristics. The weather indicator clear is another significant variable that is associated with an increased possibility of injury crashes and decreased possibility of no injury crashes. One of the past studies indicated that crashes that occurred during daytime and good weather conditions are more likely to cause major or fatal injuries [77]. Crashes that occurred in cloudy weather are found more likely for the causation of major injury crashes. This may be attributed to the ideal weather condition for aggressive driving that is being exhibited by the drivers. This result is consistent with prior investigations [40].

Crashes that occurred in normal visibility conditions are found associated with decreased possibility of no injury crashes and increased possibility of injury crashes as in case of clear weather. This finding is also evident from earlier studies [90]. Crashes that occurred at night without road lights are more likely to cause fatal injury crashes. Driving at night without road lights may result in impaired hazard perception and reaction time of the driver [80, 93, 94]. Despite driving in darkness, the low traffic volume at night time may motivate some drivers for aberrant driving such as speeding or traffic light violations [95]. These errors done by the drivers are associated with an increased possibility of severe injury crashes.

The road surface condition variable wet was found as a random significant variable. Mixed results have been demonstrated about the wet pavement surface indicator [96]. If the road is wet, the chances of crash occurrence are increased due to hydroplaning. This is consistent with past research [97], but at the same time, cautious driving is more likely in bad weather, decreasing the severity outcome of the crashes [26].

\section{Conclusions}

The focal point of this study was the determination of factors influencing severities of injuries induced to the victims by motor vehicle crashes on national highways of Pakistan. A random parameters logit model was estimated considering heterogeneity in means and variances. For the analysis purpose, crash data obtained from NH and MP was utilized. Mainly, the effect of driver demographics and behavior, crash characteristics, roadway characteristics, and environmental characteristics were considered for the analysis.

From the model estimation results, it was revealed that the probability of fatal injury to the crash victims increases when trucks are involved and when the crashes occur during the night without road lights while the probability of fatal injury to the crash victims decreases when the crashes occur during weekdays. The probability of major injury to the victims increases when the crash occurs on a horizontal curve, in the months of July and November, on Tuesday, and during cloudy weather, while the probability of major injury to the victims decreases when potholes are present in road surface. The probability of occurrence of minor injury to the victims increases when young drivers (age $<25$ years) are involved in crashes and for single-vehicle crashes, while it decreases for driver dozing at wheel, carelessness of driver, and when crash occur during AM peak hours. Probability of occurrence of no injury to the victims increases when a rickshaw (motorized three-wheeler) is involved in the crash while it decreases for crashes that are caused by overspeeding, occurring in the month of May, occurring during clear weather, and occurring during normal visibility conditions.

The eventual contribution of this study is to provide insight for prioritizing road sections for improvements and developing evidence based safety interventions for the country.

In view of the above findings, various safety measures are suggested to eliminate the injuries caused by motor vehicle crashes on national highways of Pakistan. These measures are based on the traditional 4Es (Engineering, Enforcement, Education, and Emergency services) approach. Engineering measures include the provision of a separate lane for heavy commercial vehicles, ensuring a proper geometric design of 
horizontal curves, installation of road lights on dangerous segments, and proper maintenance of roads. Enforcement measures include speed laws enforcement, introduction and implementation of hour of service regulations for commercial vehicles, and discouraging wrong-way driving. Education measures include road safety awareness campaigns utilizing various forms of media, distributing pamphlets, and organizing seminars on road safety. Emergency measures include the establishment of trauma centers along the highways and ensuring the provision of immediate first aid to the injured persons. Moreover, behavior modification programs need to be introduced for drivers exhibiting aberrant behavior.

The present study has some limitations. Crash data were obtained from reports prepared by the National Highways and Motorway Police. Despite the potential underreporting of minor and no injury crashes [98], the data used in the study are the only available data for crashes on national highways in Pakistan. Moreover, crash data for only N-5 (the longest national highway of Pakistan) were used in the study as such data is not available for other highways. Crash data for other highways need to be collected and used in the injury severity analysis in future studies.

\section{Data Availability}

All the data supporting the results of our study are available and will be provided on request (hanifullah755@ yahoo.com).

\section{Conflicts of Interest}

The authors declare no conflicts of interest.

\section{Authors' Contributions}

Conceptualization was performed by H. U. and A. A. S.; methodology was prepared by H. U. and A. F.; software was provided by $\mathrm{H}$. U.; validation was carried out by A. A. S.; formal analysis and investigation were performed by $\mathrm{H}$. U.; resources were provided by H. U. and A. A. S.; data curation was conducted by H. U. and A. A. S.; the original draft was prepared by H. U.; reviewing and editing were done by A. F. and A. A. S.; visualization was conducted by $H$. U.; supervision was carried out by A. F. and A. A. S. All authors have read and agreed to the published version of the manuscript.

\section{Acknowledgments}

The authors would like to thank Mr. Ishfaq Ahmed, DIG Motorways, $\mathrm{NH}$ and MP, for extending his help during crash data collection.

\section{References}

[1] World Health Organization, Global Status Report on Road Safety 2018, World Health Organization, Geneva, Switzerland, 2018.

[2] World Health Organization, Global Status Report on Road Safety 2015, World Health Organization, Geneva, Switzerland, 2015.

[3] A. Ahmed, B. A. Khan, M. B. Khurshid, M. B. Khan, and A. Waheed, "Estimating national road crash fatalities using aggregate data," International Journal of Injury Control and Safety Promotion, vol. 23, no. 3, pp. 249-254, 2016.

[4] A. Ahmed, Road Safety in Pakistan, National Road Safety Secretariat, Islamabad, Pakistan, 2007.

[5] Z. Batool, Attitudes towards Road Safety and Aberrant Behaviour of Drivers in Pakistan, University of Leeds, Leeds, UK, 2012.

[6] A. Rafiq, Information and Services, National Highway Authority, Islamabad, Pakistan, 2014, http://nha.gov.pk/.

[7] A. A. Hyder, Abdul Ghaffar, and T. I. Masood, "Motor vehicle crashes in Pakistan: the emerging epidemic," Injury Prevention, vol. 6, no. 3, pp. 199-202, 2000.

[8] I. Hafeez and M. A. Kamal, "Accidents black spots on highways and their low cost remedial measures," WIT Transactions on The Built Environment, vol. 101, pp. 691-700, 2008.

[9] A. Kayani, J. J. Fleiter, and M. J. King, "Achieving safe road use in a rapidly motorising country: the influence of longstanding beliefs on risky driver behaviour in Pakistan," in Proceedings of the International Conference of Applied Psychology (ICAPP 2012), Kampala, Uganda, November 2012.

[10] K. Azam, "Comparison of fatigue related road traffic crashes on the national highways and motorways in Pakistan," Journal of Engineering and Applied Sciences, vol. 33, no. 2, 2014.

[11] Z. Batool and O. Carsten, "Attitudinal segmentaion of drivers in Pakistan: the potential for effective road safety campaigns," Accident Analysis \& Prevention, vol. 114, pp. 48-54, 2018.

[12] H. M. Hammad, M. Ashraf, F. Abbas et al., "Environmental factors affecting the frequency of road traffic accidents: a case study of sub-urban area of Pakistan," Environmental Science and Pollution Research, vol. 26, no. 12, pp. 11674-11685, 2019.

[13] H. M. Rashid, A. Ahmed, B. Wali, and N. A. Qureshi, "An analysis of highway work zone safety practices in Pakistan," International Journal of Injury Control and Safety Promotion, vol. 26, no. 1, pp. 37-44, 2019.

[14] F. Outay, H. A. Mengash, and M. Adnan, "Applications of unmanned aerial vehicle (UAV) in road safety, traffic and highway infrastructure management: recent advances and challenges," Transportation Research Part A: Policy and Practice, vol. 141, pp. 116-129, 2020.

[15] M. Waseem, A. Ahmed, and T. U. Saeed, "Factors affecting motorcyclists' injury severities: an empirical assessment using random parameters logit model with heterogeneity in means and variances," Accident Analysis \& Prevention, vol. 123, pp. 12-19, 2019.

[16] N. Ahmad, "Exploring factors associated with crash severity on motorways in Pakistan," Proceedings of the Institution of Civil Engineers-Transport, Thomas Telford Ltd., London, UK, 2020. 
[17] G. Jacobs, A. Aeron-Thomas, and A. Astrop, Estimating Global Road Fatalities, TRL Limited, Crowthorne, UK, 2000.

[18] T. Yamamoto and V. N. Shankar, "Bivariate ordered-response probit model of driver's and passenger's injury severities in collisions with fixed objects," Accident Analysis \& Prevention, vol. 36, no. 5, pp. 869-876, 2004.

[19] L.-Y. Chang and H.-W. Wang, "Analysis of traffic injury severity: an application of non-parametric classification tree techniques," Accident Analysis \& Prevention, vol. 38, no. 5, pp. 1019-1027, 2006.

[20] N. Eluru, C. R. Bhat, and D. A. Hensher, "A mixed generalized ordered response model for examining pedestrian and bicyclist injury severity level in traffic crashes," Accident Analysis \& Prevention, vol. 40, no. 3, pp. 1033-1054, 2008.

[21] A. Behnood, A. M. Roshandeh, and F. L. Mannering, "Latent class analysis of the effects of age, gender, and alcohol consumption on driver-injury severities," Analytic Methods in Accident Research, vol. 3-4, pp. 56-91, 2014.

[22] A. Behnood and F. Mannering, "The effect of passengers on driver-injury severities in single-vehicle crashes: a random parameters heterogeneity-in-means approach," Analytic Methods in Accident Research, vol. 14, pp. 41-53, 2017.

[23] A. Behnood and F. Mannering, "Time-of-day variations and temporal instability of factors affecting injury severities in large-truck crashes," Analytic Methods in Accident Research, vol. 23, 2019.

[24] C. Lee and M. Abdel-Aty, "Comprehensive analysis of vehiclepedestrian crashes at intersections in Florida," Accident Analysis \& Prevention, vol. 37, no. 4, pp. 775-786, 2005.

[25] S. Boufous, C. Finch, A. Hayen, and A. Williamson, "The impact of environmental, vehicle and driver characteristics on injury severity in older drivers hospitalized as a result of a traffic crash," Journal of Safety Research, vol. 39, no. 1, pp. 65-72, 2008.

[26] Y. Xie, Y. Zhang, and F. Liang, "Crash injury severity analysis using Bayesian ordered probit models," Journal of Transportation Engineering, vol. 135, no. 1, pp. 18-25, 2009.

[27] J.-K. Kim, G. F. Ulfarsson, V. N. Shankar, and S. Kim, “Age and pedestrian injury severity in motor-vehicle crashes: a heteroskedastic logit analysis," Accident Analysis \& Prevention, vol. 40, no. 5, pp. 1695-1702, 2008.

[28] P. Savolainen and F. Mannering, "Probabilistic models of motorcyclists' injury severities in single- and multi-vehicle crashes," Accident Analysis \& Prevention, vol. 39, no. 5, pp. 955-963, 2007.

[29] K. Tsui, N. Sze, F. So, and S. Wong, "Association between drink driving and severity of crash injuries to road users," Hong Kong Journal of Emergency Medicine, vol. 17, no. 1, pp. 34-39, 2010.

[30] P. Liu and W. Fan, "Modeling head-on crash severity with drivers under the influence of alcohol or drugs (DUI) and non-DUI," Traffic Injury Prevention, vol. 21, no. 1, pp. 7-12, 2020.

[31] R. C. Gray, M. A. Quddus, and A. Evans, "Injury severity analysis of accidents involving young male drivers in Great Britain," Journal of Safety Research, vol. 39, no. 5, pp. 483-495, 2008.

[32] M. S. Shaheed, K. Gkritza, A. L. Carriquiry, and S. L. Hallmark, "Analysis of occupant injury severity in winter weather crashes: a fully Bayesian multivariate approach," Analytic Methods in Accident Research, vol. 11, pp. 33-47, 2016.

[33] M. Uddin and N. Huynh, "Truck-involved crashes injury severity analysis for different lighting conditions on rural and urban roadways," Accident Analysis \& Prevention, vol. 108, pp. 44-55, 2017.

[34] A. Ariannezhad and Y.-J. Wu, "Effects of heavy rainfall in different light conditions on crash severity during Arizona's monsoon season," Journal of Transportation Safety \& Security, vol. 11, no. 6, pp. 579-594, 2019.

[35] Z. Li, C. Chen, Q. Wu et al., "Exploring driver injury severity patterns and causes in low visibility related single-vehicle crashes using a finite mixture random parameters model," Analytic Methods in Accident Research, vol. 20, pp. 1-14, 2018.

[36] N. Casado-Sanz, B. Guirao, and M. Attard, "Analysis of the risk factors affecting the severity of traffic accidents on Spanish crosstown roads: the driver's perspective," Sustainability, vol. 12, no. 6, 2020.

[37] D. Delen, R. Sharda, and M. Bessonov, "Identifying significant predictors of injury severity in traffic accidents using a series of artificial neural networks," Accident Analysis \& Prevention, vol. 38, no. 3, pp. 434-444, 2006.

[38] D. Chimba and T. Sando, "Neuromorphic prediction of highway injury severity," Advances in Transportation Studies, vol. 19, pp. 17-26, 2009.

[39] W.-H. Chen and P. P. Jovanis, "Method for identifying factors contributing to driver-injury severity in traffic crashes," Transportation Research Record: Journal of the Transportation Research Board, vol. 1717, no. 1, pp. 1-9, 2000.

[40] H. Huang, H. C. Chin, and M. M. Haque, "Severity of driver injury and vehicle damage in traffic crashes at intersections: a Bayesian hierarchical analysis," Accident Analysis \& Prevention, vol. 40, no. 1, pp. 45-54, 2008.

[41] N. V. Malyshkina and F. L. Mannering, "Markov switching multinomial logit model: an application to accident-injury severities," Accident Analysis \& Prevention, vol. 41, no. 4, pp. 829-838, 2009.

[42] M. F. Ballesteros, P. C. Dischinger, and P. Langenberg, "Pedestrian injuries and vehicle type in Maryland, 19951999," Accident Analysis \& Prevention, vol. 36, no. 1, pp. 73-81, 2004.

[43] S. M. Rifaat and R. Tay, "Effects of street patterns on injury risks in two-vehicle crashes," Transportation Research Record, vol. 2102, pp. 61-67, 2009.

[44] A. V. Moudon, L. Lin, J. Jiao, P. Hurvitz, and P. Reeves, “The risk of pedestrian injury and fatality in collisions with motor vehicles, a social ecological study of state routes and city streets in King County, Washington," Accident Analysis \& Prevention, vol. 43, no. 1, pp. 11-24, 2011.

[45] M. de Lapparent, "Willingness to use safety belt and levels of injury in car accidents," Accident Analysis \& Prevention, vol. 40, no. 3, pp. 1023-1032, 2008.

[46] N. V. Malyshkina and F. L. Mannering, "Empirical assessment of the impact of highway design exceptions on the frequency and severity of vehicle accidents," Accident Analysis \& Prevention, vol. 42, no. 1, pp. 131-139, 2010.

[47] K. Haleem and M. Abdel-Aty, "Examining traffic crash injury severity at unsignalized intersections," Journal of Safety Research, vol. 41, no. 4, pp. 347-357, 2010.

[48] M. A. Quddus, R. B. Noland, H. C. Chin, and H. C. Chin, "An analysis of motorcycle injury and vehicle damage severity using ordered probit models," Journal of Safety Research, vol. 33, no. 4, pp. 445-462, 2002.

[49] S. Jung, X. Qin, and D. A. Noyce, "Rainfall effect on singlevehicle crash severities using polychotomous response models," Accident Analysis \& Prevention, vol. 42, no. 1, pp. 213-224, 2010. 
[50] F. L. Mannering, V. Shankar, and C. R. Bhat, "Unobserved heterogeneity and the statistical analysis of highway accident data," Analytic Methods in Accident Research, vol. 11, pp. 1-16, 2016.

[51] Y. Xiong and F. L. Mannering, "The heterogeneous effects of guardian supervision on adolescent driver-injury severities: a finite-mixture random-parameters approach," Transportation Research Part B: Methodological, vol. 49, pp. 39-54, 2013.

[52] Y. Xiong, J. L. Tobias, and F. L. Mannering, "The analysis of vehicle crash injury-severity data: a Markov switching approach with road-segment heterogeneity," Transportation Research Part B: Methodological, vol. 67, pp. 109-128, 2014.

[53] H. Zhou, C. Yuan, N. Dong, S. C. Wong, and P. Xu, "Severity of passenger injuries on public buses: a comparative analysis of collision injuries and non-collision injuries," Journal of Safety Research, vol. 74, pp. 55-69, 2020.

[54] F. Chen and S. Chen, "Injury severities of truck drivers in single- and multi-vehicle accidents on rural highways," Accident Analysis \& Prevention, vol. 43, no. 5, pp. 1677-1688, 2011.

[55] F. Chen, S. Chen, and X. Ma, "Analysis of hourly crash likelihood using unbalanced panel data mixed logit model and real-time driving environmental big data," Journal of Safety Research, vol. 65, pp. 153-159, 2018.

[56] C. F. Manski and D. McFadden, Structural Analysis of Discrete Data with Econometric Applications, MIT Press, Cambridge, MA, USA, 1981.

[57] J. C. Milton, V. N. Shankar, and F. L. Mannering, "Highway accident severities and the mixed logit model: an exploratory empirical analysis," Accident Analysis \& Prevention, vol. 40, no. 1, pp. 260-266, 2008.

[58] K. E. Train, Discrete Choice Methods with Simulation, Cambridge University Press, Cambridge, UK, 2009.

[59] P. T. Savolainen, "Examining driver behavior at the onset of yellow in a traffic simulator environment: comparisons between random parameters and latent class logit models," Accident Analysis \& Prevention, vol. 96, pp. 300-307, 2016.

[60] M. S. B. Shaheed, K. Gkritza, W. Zhang, and Z. Hans, "A mixed logit analysis of two-vehicle crash severities involving a motorcycle," Accident Analysis \& Prevention, vol. 61, pp. 119-128, 2013.

[61] A. Behnood and F. L. Mannering, "An empirical assessment of the effects of economic recessions on pedestrian-injury crashes using mixed and latent-class models," Analytic Methods in Accident Research, vol. 12, pp. 1-17, 2016.

[62] L. Aarts and I. Van Schagen, "Driving speed and the risk of road crashes: a review," Accident Analysis \& Prevention, vol. 38, no. 2, pp. 215-224, 2006.

[63] T. Abegaz, Y. Berhane, A. Worku, A. Assrat, and A. Assefa, "Effects of excessive speeding and falling asleep while driving on crash injury severity in Ethiopia: a generalized ordered logit model analysis," Accident; Analysis and Prevention, vol. 71, 2014.

[64] P. Vayalamkuzhi and V. Amirthalingam, "Influence of geometric design characteristics on safety under heterogeneous traffic flow," Journal of Traffic and Transportation Engineering (English Edition), vol. 3, no. 6, pp. 559-570, 2016.

[65] I. Ajzen, "The theory of planned behavior," Organizational Behavior and Human Decision Processes, vol. 50, no. 2, pp. 179-211, 1991.

[66] M. Castro, R. Paleti, and C. R. Bhat, "A spatial generalized ordered response model to examine highway crash injury severity," Accident Analysis \& Prevention, vol. 52, pp. 188203, 2013.
[67] Y. Xie, K. Zhao, and N. Huynh, "Analysis of driver injury severity in rural single-vehicle crashes," Accident Analysis \& Prevention, vol. 47, pp. 36-44, 2012.

[68] R. B. Hanrahan, P. M. Layde, S. Zhu, C. E. Guse, and S. W. Hargarten, "The association of driver age with traffic injury severity in Wisconsin," Traffic Injury Prevention, vol. 10, no. 4, pp. 361-367, 2009.

[69] G. Li, E. R. Braver, and L.-H. Chen, "Fragility versus excessive crash involvement as determinants of high death rates per vehicle-mile of travel among older drivers," Accident Analysis \& Prevention, vol. 35, no. 2, pp. 227-235, 2003.

[70] A. Bener, "The relationship between four-wheel drives and risky driving behaviours," International Journal of Medicine and Public Health, vol. 4, p. 3, 2014.

[71] A. Bener, E. Yildirim, T. Özkan, and T. Lajunen, "Driver sleepiness, fatigue, careless behavior and risk of motor vehicle crash and injury: population based case and control study," Journal of Traffic and Transportation Engineering (English Edition), vol. 4, no. 5, pp. 496-502, 2017.

[72] L. Evans, Traffic Safety and the Driver, Science Serving Society, Washington, DC, USA, 1991.

[73] Z. Zheng, P. Lu, and B. Lantz, "Commercial truck crash injury severity analysis using gradient boosting data mining model," Journal of Safety Research, vol. 65, pp. 115-124, 2018.

[74] X. Zhu and S. Srinivasan, "A comprehensive analysis of factors influencing the injury severity of large-truck crashes," Accident Analysis \& Prevention, vol. 43, no. 1, pp. 49-57, 2011.

[75] G. Fountas, A. Fonzone, N. Gharavi, and T. Rye, "The joint effect of weather and lighting conditions on injury severities of single-vehicle accidents," Analytic Methods in Accident Research, vol. 27, 2020.

[76] U. Schmucker, R. Dandona, G. A. Kumar, and L. Dandona, "Crashes involving motorised rickshaws in urban India: characteristics and injury patterns," Injury, vol. 42, no. 1, pp. 104-111, 2011.

[77] M. Kamruzzaman, "Analysis of traffic injury severity in a mega city of a developing country," in Proceedings of the 4th Road Safety International Conference, Sydney, Australia, March 2013.

[78] C. J. O'donnell and D. H. Connor, "Predicting the severity of motor vehicle accident injuries using models of ordered multiple choice," Accident Analysis \& Prevention, vol. 28, no. 6, pp. 739-753, 1996.

[79] K. Obeng, "Injury severity, vehicle safety features, and intersection crashes," Traffic Injury Prevention, vol. 9, no. 3, pp. 268-276, 2008.

[80] C. Y. Chan, B. Huang, X. Yan, and S. Richards, "Investigating effects of asphalt pavement conditions on traffic accidents in Tennessee based on the pavement management system (PMS)," Journal of Advanced Transportation, vol. 44, no. 3, pp. 150-161, 2010.

[81] Y. Li, C. Liu, and L. Ding, "Impact of pavement conditions on crash severity," Accident Analysis \& Prevention, vol. 59, pp. 399-406, 2013.

[82] S. Chen, T. U. Saeed, and S. Labi, "Impact of road-surface condition on rural highway safety: a multivariate random parameters negative binomial approach," Analytic Methods in Accident Research, vol. 16, pp. 75-89, 2017.

[83] W. Hao, C. Kamga, and D. Wan, "The effect of time of day on driver's injury severity at highway-rail grade crossings in the United States," Journal of Traffic and Transportation Engineering (English Edition), vol. 3, no. 1, pp. 37-50, 2016. 
[84] J. R. Klop and A. J. Khattak, "Factors influencing bicycle crash severity on two-lane, undivided roadways in North Carolina," Transportation Research Record, vol. 1674, pp. 78-85, 1999.

[85] J.-K. Kim, "Bicyclist injury severities in bicycle-motor vehicle accidents," Accident Analysis \& Prevention, vol. 39, no. 2, pp. 238-251, 2007.

[86] N.-N. Sze and S. C. Wong, "Diagnostic analysis of the logistic model for pedestrian injury severity in traffic crashes," Accident Analysis \& Prevention, vol. 39, pp. 1267-1278, 2007.

[87] C.-W. Pai, "Motorcyclist injury severity in angle crashes at T-junctions: identifying significant factors and analysing what made motorists fail to yield to motorcycles," Safety Science, vol. 47, pp. 1097-1106, 2009.

[88] M. A. Quddus, C. Wang, and I. Stephen, Impact of Road Traffic Congestion On Crash Severity Using Ordered Response Models. No. 09-0793, American Society of Civil Engineers, Reston, VA, USA, 2009.

[89] M. Abdel-Aty, "A study on crashes related to visibility obstruction due to fog and smoke," Accident Analysis \& Prevention, vol. 43, pp. 1730-1737, 2011.

[90] C. M. Farmer and A. F. Williams, "Temporal factors in motor vehicle crash deaths," Injury Prevention, vol. 11, pp. 18-23, 2005.

[91] S. Islam and S. L. Jones, "Pedestrian at-fault crashes on rural and urban roadways in Alabama," Accident Analysis \& Prevention, vol. 72, pp. 267-276, 2014.

[92] A. K. Jägerbrand and S. Jonas, "Effects of weather conditions, light conditions, and road lighting on vehicle speed," SpringerPlus, vol. 5, pp. 1-17, 2016.

[93] F. Fylan, "Why do people drive when they can't see clearly?" Transportation Research Part F: Traffic Psychology and Behaviour, vol. 56, pp. 123-133, 2018.

[94] E. de Bellis, "Blind haste: as light decreases, speeding increases," PLoS One, vol. 13, Article ID e0188951, 2018.

[95] F. Malin, I. Norros, and S. Innamaa, "Accident risk of road and weather conditions on different road types," Accident Analysis \& Prevention, vol. 122, pp. 181-188, 2019.

[96] B. Dong, X. Ma, F. Chen, and S. Chen, "Investigating the differences of single-vehicle and multivehicle accident probability using mixed logit model," Journal of Advanced Transportation, vol. 2018, Article ID 2702360, 9 pages, 2018.

[97] V. Shankar, F. Mannering, and W. Barfield, "Statistical analysis of accident severity on rural freeways," Accident Analysis \& Prevention, vol. 28, pp. 391-401, 1996.

[98] J. A. Bhatti, "Differences in police, ambulance, and emergency department reporting of traffic injuries on Karachi-Hala road, Pakistan," BMC Research Notes, vol. 4, pp. 1-7, 2011. 